\title{
ESPAÇO FÍSICO ESCOLAR NA EDUCAÇÃO AMBIENTAL DE CRIANÇAS EM PROL DO FUTURO SUSTENTÁVEL
}

\author{
Ana Claudia Mansano Girotto 1 \\ Bianca Ramos Meira ${ }^{2}$ \\ Marla Simone Bueno Ribeiro ${ }^{3}$ \\ Maria de los Angeles Perez Lizama ${ }^{4}$ \\ Rute Grossi-Milani ${ }^{5}$
}

Resumo: $O$ estudo visa a apresentar ações de criação e implantação de espaços educadores sustentáveis em uma escola municipal no Estado do Mato Grosso com a finalidade de estimular a Educação Ambiental e a sustentabilidade. Trata-se de uma pesquisa aplicada, pautada no uso de metodologias ativas de ensino e técnicas lúdicas de aprendizado, envolvendo acadêmicos de Arquitetura e Urbanismo e a comunidade escolar. O projeto foi desenvolvido de modo a possibilitar proteção relativa às intempéries climáticas e maior conforto térmico, assim como oportunizar a aplicação de atividades lúdicas direcionadas à Educação Ambiental e sensibilizar os indivíduos para problemas atuais e futuros na esfera ambiental, intencionando uma sociedade mais consciente e sustentável pós-pandemia.

Palavras-chave: Educação Ambiental; Espaços Escolares; Desenvolvimento Infantil.

1 Universidade Cesumar. E-mail: mansanoana@hotmail.com. Link para o Lattes: http://lattes.cnpq.br/2734550166977165

2 Universidade Cesumar. E-mail: bianca.rmeira@hotmail.com. Link para o Lattes: http://lattes.cnpq.br/8527226743705523

3 Universidade Cesumar. E-mail: marla.arquitetura@terra.com.br. Link para o Lattes: http://lattes.cnpq.br/8176498155136718

4 Universidade Cesumar/Instituto Cesumar de Ciência, Tecnologia e Inovação.

E-mail: maria.lizama@unicesumar.edu.br, Link para o Lattes: http://lattes.cnpq.br/7827450324471754

5 Universidade Cesumar/ Instituto Cesumar de Ciência, Tecnologia e Inovação.

E-mail: rutegrossimilani@gmail.com, Link para o Lattes: http://lattes.cnpq.br/8844448878404124 
Abstract: The study aims to present actions to create and implement sustainable educational spaces in a municipal school in the State of Mato Grosso in order to stimulate environmental education and sustainability. It is an applied research, based on the use of active teaching methodologies and playful learning techniques, involving academics of Architecture and Urbanism and the school community. The project was developed in order to provide protection related to the weather and greater thermal comfort, as well as providing opportunities for the application of recreational activities aimed at environmental education and sensitizing individuals to current and future problems in the environmental sphere, intending a more conscious and sustainable society post-pandemic.

Keywords: Environmental Education; School Spaces; Child Development.

\section{Introdução}

As alterações do clima no mundo se intensificaram nos últimos 200 anos em decorrência da industrialização, impulsionadas diretamente pela ação humana, desencadeando inúmeras transformações ambientais (ZHAO; HE; MENG, 2015). Entre os impactos devidos às mudanças climáticas, é possível observar o aumento da temperatura global, a ocorrência de eventos extremos e alterações nos padrões de chuvas e secas (CLAYTON et al., 2015; PINHEIRO et al., 2018). Além de afetarem os ecossistemas, as mudanças climáticas impactam a vida humana, promovendo alterações psicológicas, comportamentais, político-econômicas e socioculturais (GIFFORD, 2008; WHITMARSH, 2011).

Estudos apontam que a elevação da temperatura global pode ocasionar um aumento dos agentes infecciosos, propiciando condições ideais para vetores e patógenos sobreviverem em áreas antes inóspitas para eles (CURSEU et al., 2010). As alterações ambientais geradas pelas mudanças climáticas podem ser responsáveis por mutações sofridas em diversos tipos de vírus, como, por exemplo, o Influenza (CURSEU et al., 2010).

Atualmente, uma pandemia global afeta toda a população humana por causa do surgimento de uma nova doença infecciosa da família coronavírus, nomeada de COVID-19, identificada primeiramente em Wuhan, China, em dezembro de 2019, e que se espalhou rapidamente por todo o mundo (CHEN et al., 2020; MUHAMMAD et al., 2020). Ante a crise climática e sanitária enfrentada mundialmente, a sociedade contemporânea deve se engajar em comportamentos sustentáveis a fim de evitar problemas semelhantes no futuro.

$\mathrm{Na}$ tentativa de evitar a degradação ambiental, em âmbito mundial são envidados esforços e iniciativas por meio de programas, organizações, instituições, departamentos, normas, tratados e conferências que enfatizam a importância do meio ambiente, da Educação Ambiental e do desenvolvimento sustentável. A Conferência das Nações Unidas sobre o meio ambiente e o desenvolvimento sustentável no ano de 1992, caracterizada como Rio-92, 
abordou ações de planejamento para o desenvolvimento sustentável de sociedades no século XXI, junto com medidas socioeconômicas e ambientais (PATO; DELABRIDA, 2019). O acordo de Paris, em 2015, reconheceu as mudanças climáticas como uma ameaça eminente e potencialmente irreversível para o planeta, englobando esforços para minimizar o aumento da temperatura e fortalecer os países que enfrentam os impactos dessas mudanças (REI; GONÇALVES; DE SOUZA, 2017).

Também em 2015, as Nações Unidas apresentaram alguns parâmetros para melhorar a vida na Terra, a "Agenda 2030", que envolve medidas para o desenvolvimento sustentável como: gerar bem-estar a todos, proteger o meio ambiente e enfrentar as mudanças climáticas, que resultaram em 17 objetivos de desenvolvimento sustentável (ODS). Entre os objetivos destacam-se a educação de qualidade por sua finalidade de "assegurar a educação inclusiva $e$ equitativa e de qualidade, e promover oportunidades de aprendizagem ao longo da vida para todas e todos" (ONU, 2015).

Tais documentos sinalizam a crise ambiental como altamente impactante para o planeta e os seres humanos; exigem estudos e discussões relacionados às atitudes humanas. A Educação Ambiental surge como uma necessidade $e$ esperança (COIMBRA; FERNANDES, 2017), na perspectiva de que o ambiente influencia e é influenciado por seus integrantes. Portanto, a compreensão da Educação Ambiental se faz relevante para que tanto o espaço físico quanto os que nele vivem estejam engajados na promoção da sustentabilidade (CAVALCANTE; ELALI, 2018).

A desconexão entre o ambiente natural e o ser humano gera indiferença em preservar e cuidar do meio ambiente. Nesse sentido, defende-se a necessidade de medidas que realizem essa conexão com o objetivo de propiciar vivências com a natureza assim como atitudes pró-ambientais. Dessa forma, a implantação da Educação Ambiental no ensino, de espaços verdes e áreas livres norteia a construção de escolas sustentáveis pós-pandemia e se torna primordial para o desenvolvimento pró-ambiental do ser humano (HIGUCHI; KUHNEN; PATO, 2019).

Considera-se que investir em uma Educação Ambiental de qualidade é um modo de se construir uma sociedade sustentável pós-pandemia. Nesse âmbito, visando a um futuro com base no desenvolvimento sustentável e relacionando ações voltadas à Educação Ambiental, de forma interdisciplinar, propõe-se a reflexão: Que ações podem ser promovidas no espaço físico escolar que estimulem a Educação Ambiental?

Diante do exposto, neste estudo busca-se apresentar ações de criação e implantação de espaços educadores sustentáveis em uma escola municipal localizada no Estado do Mato Grosso com a intenção de estimular a Educação Ambiental e a sustentabilidade em prol do futuro sustentável. 


\section{Revisão da literatura}

\section{Educação Ambiental e espaços verdes escolares}

A Educação Ambiental surgiu em meados da década de 1960 e início da década de 1970, como resposta ao movimento ecológico na esfera educativa quando se passou a pontuara as relações entre eventos ambientais e comportamento humano e suas consequências para a humanidade (PATO; DELABRIDA, 2019). A Educação Ambiental ganhou destaque na história como indicativo da necessidade de respostas aos desafios atuais, ou seja, a dinâmica das relações entre ser humano e natureza.

No Brasil, a Educação Ambiental foi enfatizada na década de $1980 \mathrm{com}$ os movimentos sociais e organizações não governamentais (ONGs) ambientalistas. O estudo da Educação Ambiental foi intensificado com a publicação da Política Nacional de Educação Ambiental, Lei 9795/99, de 27 de abril de 1999. Essa Lei foi um marco no país e no cenário internacional, pois instituiu normativas que se tornaram referência no estudo da área (PATO; DELABRIDA, 2019). Em 2002, a Lei foi regulamentada e teve início a instalação do órgão gestor desse planejamento, concretizado em 2003. Após anos de discussão entre educadores ambientais e gestores municipais, em 2005 foi criado o novo Programa Nacional de Educação Ambiental (Pronea), e a partir de então observou-se aumento no número de normativas municipais, estaduais e federais, além de documentações técnicas referentes à Educação Ambiental (DE SOUZA, 2018).

Atualmente, a Educação Ambiental engloba não apenas o ambiente físico, mas o modo adequado de inserir o sujeito nesse ambiente, no contexto sociopolítico e econômico. A Educação Ambiental crítica é um processo para desenvolver a ética em respeito a todas as formas de vida, agregando conhecimento, valores e ações que são convertidos em oportunidades educativas.

A Educação Ambiental, portanto, centra-se na atitude humana, de maneira a orientar o que fazer, como e por que, internalizar esse sistema de valores sustentáveis, relacionar a pessoa ao ambiente e inserir o conhecimento técnico com as atitudes para a formação ambiental do ser humano (PATO; DELABRIDA, 2019). O objetivo é criar indivíduos consolidados na cidadania ativa relativa às questões ambientais para que essas ações permaneçam ao longo dos anos (DA SILVA; CALIXTO, 2017).

A preocupação ambiental está acima dos conteúdos pedagógicos, possibilitando aos seres humanos interagir entre si, o que resulta em troca de práticas e conhecimentos. Matérias específicas que orientem o estudo dos problemas vinculados ao meio ambiente são alternativas para alcançar modificações nas atitudes e promover pensamentos e ações mais sustentáveis (PATO; DELABRIDA, 2019). Por meio da implantação dos conceitos ambientais nas escolas, o número de alunos envolvidos na defesa do meio ambiente se tornaria cada vez maior, incentivando a percepção ecológica dos 
jovens e tornando-os cada vez mais conscientes, saudáveis e envolvidos nas questões socioambientais (TEIXEIRA; MARQUES; PEREIRA, 2017).

No ambiente escolar, há diferentes formas para a inclusão da Educação Ambiental, como atividades artísticas, experiências práticas, atividades extras sala de aula e produção de materiais locais e projetos. Dessa forma, a equipe pedagógica tem a possibilidade de propor novas metodologias que favoreçam a implantação da Educação Ambiental em prol do desenvolvimento do aluno, sensibilizando-o de seu papel na preservação da natureza e valorização da biodiversidade (DOS SANTOS, 2016). A Educação Ambiental deve estabelecer um foco transdisciplinar, em que as diferentes disciplinas trabalhem conjuntamente em todos os estágios educacionais, seja na investigação de um problema ou na implementação de uma intervenção (MOSER, 2005).

A promoção de ambientes seguros, saudáveis e sustentáveis em toda a escola é encorajada, visto que o ambiente escolar é considerado um elemento básico no contexto da aprendizagem, alcançando resultados positivos em diversos países (SILVA PIÑEIRO, 2018). Ademais, a interação pessoaambiente estimula os sentidos, possibilita o aprimoramento de competências e sociabilidade, propicia sensações de segurança e autoconfiança e promove a identidade pessoal (CAMPOS-DE-CARVALHO; ROSSETTI-FERREIRA, 1993; PATO; DELABRIDA, 2019).

A implementação de espaços verdes na escola, como hortas e jardins sensoriais, constitui uma maneira eficiente de facilitar a Educação Ambiental nas escolas, já que o contato com a natureza fornece inúmeros benefícios, como restauração psicológica, redução dos níveis de estresse, bem-estar físico e mental (HERZO et al., 2003; THOMPSON et al., 2012; WOLSINK, 2016), além de promover sustentabilidade e comportamento pró-ambiental por meio do conhecimento sobre os serviços ecossistêmicos, ou seja, os elementos que a natureza fornece que são essenciais para a sociedade humana (COSTANZA et al., 1997; WOLSINK, 2016).

É importante salientar que os ambientes escolares tiveram, ao longo dos anos, seu significado reconstruído, readequando a visão para além de suas dimensões geométricas e interligando as dimensões sociais. Os espaços são abundantes em símbolos e significados de todas as pessoas que nele convivem, constituído de significados culturais, morais e afetivos. Assim, os espaços escolares possuem normas e valores que mesmo aparentemente não explícitos são repassados para todos de forma lúdica. O ambiente escolar deve conter características para que seja possível o desenvolvimento da prática pedagógica coerente. A atitude de ensinar e a consequência de aprender necessitam de condições positivas tanto para o docente quanto para 0 discente. Nesse contexto, é fundamental o estudo e a implantação da Educação Ambiental (RIBEIRO, 2004; COELHO, 2015).

Cabe à escola pesquisar e implantar de maneira efetiva a Educação Ambiental, tornando possível a aprendizagem de modo interdisciplinar (DOS SANTOS, 2016). Nessa direção, é responsabilidade da escola proporcionar um 
ambiente escolar saudável, sustentável e coerente, relacionado com o que se pretende ensinar aos seus alunos, para contribuir de fato para a formação da identidade ambiental e seres humanos conscientes de suas responsabilidades com o meio ambiente (VASCONCELOS, 2017).

\section{Espaços Educadores Sustentáveis e Promotores de Saúde}

As escolas sustentáveis possuem a característica de inter-relacionar as atividades ali geradas com os impactos ao meio ambiente, buscando aplicar inovações tecnológicas e infraestrutura para o uso adequado da água e energia, saneamento e destinação adequada dos resíduos. Desse modo, ambientes que ensinam passam a integrar ações para a qualidade de vida e sustentabilidade (MEC, 2013).

Os espaços educadores sustentáveis nas escolas são valorizados no mundo todo, além de incentivarem o pensamento crítico e inovador na área da Educação Ambiental (GROHE, 2014). Em 2007, nos Estados Unidos, a Green Building Council (Conselho de Construção Verde) lançou a campanha nacional de escolas verdes e o centro de escolas verdes, com o interesse de contemplar o desempenho e o bem-estar dos alunos, a Educação Ambiental, a eficiência de recursos e a redução de dióxido de carbono. Ou seja, as escolas sendo pensadas como locais saudáveis para estimular e desenvolver o aprendizado e ao mesmo tempo fornecer melhoria energética (CHAWLA et al., 2014).

As escolas verdes se caracterizam por melhorar a qualidade do ar, minimizar os gastos com energia, oferecer iluminação e acústica adequada nas salas de aulas, diminuir o uso da água potável, reutilizar a água da chuva e iniciativas de reciclagem. Esses são fatores determinantes para o aumento da autoconfiança de crianças e adolescentes nos ambientes escolares, melhora no desempenho acadêmico e redução do estresse. Ao mesmo tempo, contribui para a proteção e preservação do meio ambiente em toda a comunidade (CHAWLA et al., 2014; ZHAO; HE; MENG, 2015).

No Brasil, pode-se citar o Colégio Estadual Erich Walter Heine do Rio de Janeiro, que obteve a certificação Leed (Leadership in Energy and Environmental Design) concedida pela organização internacional Green Building Council (GBC) (BARATTO, 2014). "Essa certificação busca incentivar a transformação dos projetos, obras e operação das edificações com foco na sustentabilidade, objetivando a adoção de práticas de construção sustentável" (GBC Brasil, 2012).

Esse colégio possui uma estrutura que visa à redução do consumo de energia e aplica mais de 50 medidas para maximizar o aproveitamento de recursos naturais e eficiência energética, tais como: energia solar, coleta seletiva e dispositivos que captam a água da chuva a ser usada nos sanitários, jardins e limpeza da escola (BARATTO, 2014). Além disso, possui um pavimento permeável do estacionamento que possibilita a passagem da água $e$ do ar e um telhado verde, onde a vegetação diminui a absorção do calor e 
absorve a água da chuva (BARATTO, 2014). Como resultado, o colégio alcançou economia de $50 \%$ da água potável e, com a instalação de lâmpadas de led em todo o edifício, reduziu em até $80 \%$ o consumo de energia.

A implantação de espaços verdes na escola se articula amplamente à proposta de criação de espaços educadores sustentáveis, visto a importância da interação com a natureza e do acesso à infraestrutura verde (RIBEIRO et al., 2019). Em diversas cidades pelo mundo, estudos confirmam a associação do desenvolvimento infantil ao espaço escolar e ao ambiente de inserção (RIBEIRO et al., 2019). Assim como, pesquisas relatam que a presença da natureza causa efeitos positivos cognitivos, aumenta a concentração e a atenção dos alunos.

Estudos demonstram que a vegetação está associada às altas pontuações acadêmicas e ao aprimoramento da concentração. A experiência direta com a natureza, por meio de brincadeiras e exploração, desenvolve a aptidão motora, melhorando o equilíbrio e a coordenação (MUSTAPA; MALIKI; HAMZAH, 2015).

O estudo realizado por Kweon et al. (2017) evidenciou os fatores ambientais da escola, em que, mediante a análise da vegetação no ambiente escolar, percebeu-se a influência de modo positivo os alunos. As características da vegetação demonstram que as árvores, em comparação à grama e aos arbustos, têm associação significativa e positiva no desempenho acadêmico dos alunos e são essenciais para a vida saudável das crianças na escola (KWEON et al., 2017). Essa análise evidenciou que os alunos se interessam por conhecer mais sobre o mundo natural, a biodiversidade, a origem dos alimentos naturais, frutas, vegetais, laticínios e carnes, como são produzidos e a entender todo o processo. Trata-se de conhecimento fundamental para compreender questões relacionadas à biodiversidade e ao meio ambiente, fatores que geram maior conscientização, interesse, saúde e bem-estar infantil (FISCHER et al., 2019).

Nesse sentido, reitera-se que o espaço escolar é fundamental para o desenvolvimento sustentável social, com a destinação de espaços verdes, atividades e ações que fomentem diálogos e práticas focadas no bem-estar social e ambiental. O espaço educador sustentável aprimora a eficiência no uso de recursos naturais, reduz o consumo de água e energia e o desperdício de alimentos (MEC, 2013).

\section{Materiais e Métodos}

\section{Delineamento do estudo}

Trata-se de pesquisa aplicada, pautada no uso de metodologias ativas de ensino e técnicas lúdicas de aprendizado envolvendo acadêmicos do curso de Arquitetura e Urbanismo da Unifasipe (Centro Universitário Fasipe) e os alunos da escola solicitante do projeto já descrita. O objetivo é possibilitar a 
promoção de comportamentos pró-ambientais alicerçada nos princípios da Educação Ambiental crítica e transformadora, fomentando a integração entre processos de sensibilização, aprendizado, questionamento e conscientização, envolvendo todas as idades (DA SILVA et al., 2015).

Os acadêmicos do curso referido empreenderam o levantamento da problematização via reunião com a responsável pela Instituição de ensino (IE). Com base nos direcionamentos do Plano de Necessidades sugerido, foram levantados os pontos mais importantes e determinantes para o projeto de arquitetura. Os acadêmicos foram direcionados à reflexão sobre possíveis causas e efeitos dos problemas e necessidades apontados, promovendo o estudo de caso, materiais e possibilidades projetuais. A metodologia ativa viabiliza resposta crítica e criativa conectada às necessidades determinadas e explora as possíveis soluções para a intervenção (DA SILVA; MIGUEL; TEIXEIRA, 2011).

O projeto foi solicitado ao Escritório Modelo de Arquitetura e Urbanismo (Emau) da Unifasipe (Instituição de Ensino Superior Privada - IES) por uma escola municipal localizada em Sinop, cidade da região norte do Estado do Mato Grosso. A escola atende crianças da $1^{\mathrm{a}}$ à $5^{\mathrm{a}}$ série do Ensino Fundamental em período integral. O Emau é projeto de extensão universitário, unido à pesquisa e à graduação, desenvolvido pela IES para auxiliar na formação prática dos acadêmicos do curso de Arquitetura e Urbanismo para complementar a educação universitária e afirmar um compromisso com a realidade social da comunidade (FENEA, 2007).

Após o contato da diretora da escola municipal com a supervisora do Emau, foi agendada reunião para conversa inicial acerca do Plano de Necessidades de reforma, conforme sugerido pela IE municipal. Foram selecionados três acadêmicos do curso de Arquitetura e Urbanismo para participar do projeto, ficando estes responsáveis pelas medições físicas, levantamento de necessidades junto à direção da escola e desenvolvimento do projeto, sempre acompanhados pela docente supervisora da disciplina de Estágio Supervisionado responsável pelo Emau.

Em um dia previamente agendado, efetuaram-se reunião e uma primeira visita técnica para levantamento das informações ao direcionamento do projeto de arquitetura. No total, foram necessárias duas visitas técnicas para medição do espaço físico.

O envolvimento dos estudantes de Arquitetura e Urbanismo está vinculado à prática do projeto de reforma e implantação técnica solicitado pela $\mathrm{IE}$, devendo estes realizar pesquisas atinentes às tipologias de ambientes que deveriam ser propostas, saindo do usual e com limitações de custo, ampliando o conhecimento em pesquisa e técnico/projetual. A elaboração do projeto de arquitetura e sua implantação integram o processo educativo e contribui para a disseminação do conhecimento relativo ao ambiente, enfatizando a prática e o envolvimento sociais (DA SILVA et al., 2015). 


\section{Local do Estudo}

Este estudo foi elaborado levando-se em consideração a realidade vivenciada pela população da região Norte do Estado de Mato Grosso, a qual abrange o bioma Amazônia, com vegetação de floresta semidecidual, considerada a maior reserva de madeira tropical do mundo. Assinala-se que os últimos 5 anos têm sido marcados por um número crescente de focos de queimada nos biomas que compõem o Estado do Mato Grosso: Amazônia, cerrado e pantanal (JESUS et al., 2020).

O desequilíbrio ambiental ocasiona alteração nos índices pluviométricos da região e contribui com o aumento do período da seca e suas características, o que torna mais propícia a dispersão do fogo (JESUS et al., 2020). Essa realidade é preocupante diante dos problemas ambientais e de saúde desencadeados pelas queimadas, e o incentivo à Educação Ambiental pode ser fator de grande relevância quando se considera a relação com o controle dos agentes causadores.

O clima da região é tropical, marcado por aspectos bem definidos de chuva e seca; a temperatura é elevada, normalmente variando entre $22^{\circ} \mathrm{C}$ e $28^{\circ} \mathrm{C}$, característica de clima equatorial úmido pela proximidade de algumas áreas à linha do Equador. A alteração dos níveis pluviométricos causados pelo desequilíbrio ambiental prejudica a região, pois a intensidade do período das chuvas vincula-se ao nível dos rios; consequentemente, algumas áreas podem ser alagadas ou não, interferindo no equilíbrio do bioma (MORAES, 2020) e nas comunidades biológicas que dependem desse bioma para sobreviver.

\section{Direcionamento para o projeto de arquitetura - Espaço existente e Plano de Necessidades}

A primeira visita técnica presencial possibilitou aos acadêmicos relacionar os ambientes existentes na escola, para os quais foi solicitada a intervenção e pertencentes ao ambiente externo: espaço de piso cimentado aberto e coberto com tenda deteriorada pela ação do tempo, quadra de atividades com piso cimentado, corredor lateral às salas de aulas e corredor perto dos sanitários externos.

Os acadêmicos envolvidos observaram a existência de cobertura conhecida como tenda, contando com estrutura em boas condições de conservação. Os demais materiais seriam adquiridos em prazo prédeterminado após a elaboração do projeto. Esses fatos foram norteadores para a ideia central do projeto de reforma.

O plano de necessidades determinado pela escola englobava a permanência dos espaços abertos; no entanto, esses ambientes deveriam propiciar proteção relativa às intempéries e maior conforto térmico, oportunizando o desenvolvimento e a aplicação de atividades lúdicas direcionadas à Educação Ambiental, bem como desenvolvimento psicomotor e 
relacionamento interpessoal. Outra solicitação feita pela instituição de ensino foi que o projeto proporcionasse aprendizado, relacionando temas sobre sustentabilidade e Educação Ambiental.

A necessidade exposta pela instituição de ensino era de ambiente coberto para realização das atividades lúdicas de leitura, utilização de jogos (construídos pelos próprios alunos) e estação de desenvolvimento psicomotor para os alunos com idades menores. Ainda fizeram parte das solicitações e plano de necessidades a inclusão de um escovódromo, que possibilitasse o aprendizado da higiene bucal nos menores, e a reforma de espaço considerado como quadra de atividades descoberta, que permitisse trabalhar com as crianças em atividades de roda, bola queimada, amarelinha, serpentina de números, atividades que retomassem as brincadeiras antigas e pouco vivenciadas nos dias de hoje.

Também foi solicitado um espaço para os alunos maiores com mesas de jogos, em que estes pudessem ficar integrados aos mais novos, além de incentivar o aprendizado de jogos como dama, xadrez e jogo da velha. A integração entre as idades seria realizada de forma programada e supervisionada, propiciando o relacionamento saudável com os alunos menores, oportunizando o sentido de responsabilidade e empoderamento diante dos cuidados necessários e orientados pelas professoras.

Diante das limitações financeiras da IE, foi exigida criatividade por parte dos acadêmicos, estimulando a busca por materiais adequados a cada ambiente, e pesquisa sobre durabilidade, resistência e manutenção de cada situação escolhida com o objetivo de sensibilizar os alunos para 0 comportamento mais sustentável.

\section{Resultados}

\section{Criação e desenvolvimento da proposta}

Com a necessidade apresentada pela diretora da IE de viabilizar a Educação Ambiental e o desenvolvimento psicomotor das crianças, os acadêmicos observaram ser oportuna a elaboração de jardim sensorial. Esse tema poderia ser aplicado na proposta, principalmente diante da solicitação de incentivo ao desenvolvimento cognitivo, psicomotor e Educação Ambiental. Esse ambiente seria trabalhado com variações de texturas no piso (bolinhas de gude, rolhas, cascas de pinus, pedrinhas de aquário/rio, tampinhas de refrigerante, tampinhas de garrafa pet, entre outras possibilidades) e floreiras com plantas aromáticas, viabilizando a associação entre alimentação saudável e educação nutricional, verificando também critérios envolvendo a Educação Ambiental, contribuindo dessa forma com o aprendizado e complemento do plano de necessidades observado pela IE.

O objetivo dos jardins sensoriais ou terapêuticos é permitir aos usuários um local que proporcione a experiência sensorial de bem estar, de grande 
importância para a saúde. Estimulam a sociabilidade, promovem oportunidades de relaxamento e contemplação e contribuem com o restauro do corpo e da mente (CONSTANTINO, 2010).

Durante a reunião, a diretora sugeriu a utilização de materiais reciclados em algum momento do projeto, mostrando oportuno o envolvimento das crianças e pais tanto na arrecadação como na implantação do projeto de arquitetura, proporcionando o sentimento de pertencimento nos envolvidos. Nesse sentido, após pesquisas referentes à utilização de materiais reciclados em mobiliário, constatou-se a oportunidade de aplicação da seguinte proposta:

- Caixas de frutas de madeira e plástico - para confecção de prateleiras de livros (espaço coberto) e dos cochos (floreiras) para o jardim sensorial;

- Bobinas de fios de lojas de materiais elétricos - para confecção das mesas de brincadeiras do espaço coberto;

- Pneus de diversos tamanhos - para a confecção das bases para as pias do escovódromo, suporte para espelho do mesmo ambiente, mesas de jogos e banquetas para os alunos maiores no ambiente descoberto;

- Materiais diversos - para execução do piso do jardim sensorial: bolinhas de gude, rolhas, cascas de pinus, pedrinhas de aquário/rio, tampinhas de refrigerante, tampinhas de garrafa pet.

O projeto de arquitetura buscou criar o sentimento de pertencimento e integração dos alunos mais velhos para com os mais novos, influenciando o sentimento de corresponsabilidade e valorização do próximo, assim como um ambiente agradável para as atividades externas, com condições adequadas de conforto, de maneira que os professores pudessem ensinar de forma mais divertida e lúdica.

Pensou-se na demanda por ambientes mais humanizados, trabalhados de forma pedagógica e restauradora, que proporcionassem o desenvolvimento de socialização e da Educação Ambiental. Os acadêmicos julgaram oportuna a elaboração do projeto seguindo raciocínio modular, por meio de ambientações e setorização de atividades, permitindo que pudesse ser reproduzido em outras situações de locação, por outras IE.

As Figura 1 e 2 apresenta o espaço lúdico da escola, as características do ambiente antes e depois da intervenção pelo projeto. 


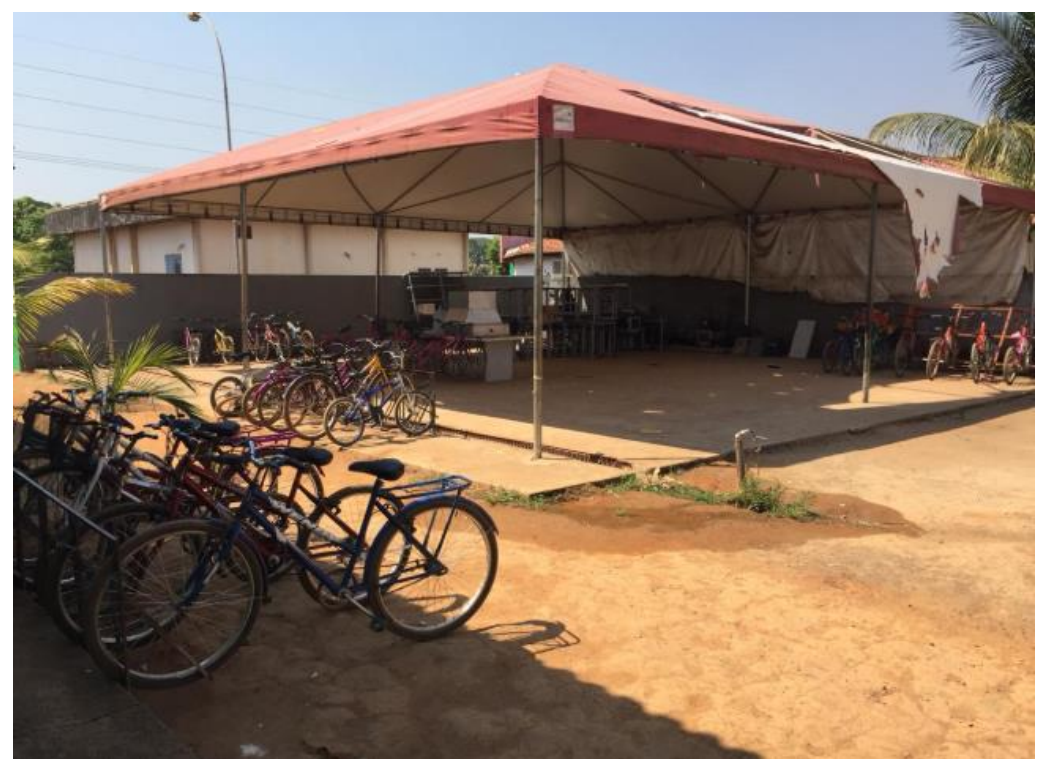

Figura 1: Local de intervenção para elaboração do espaço em uma escola municipal, no município de Sinop, MT. Fonte: Autores (2020).

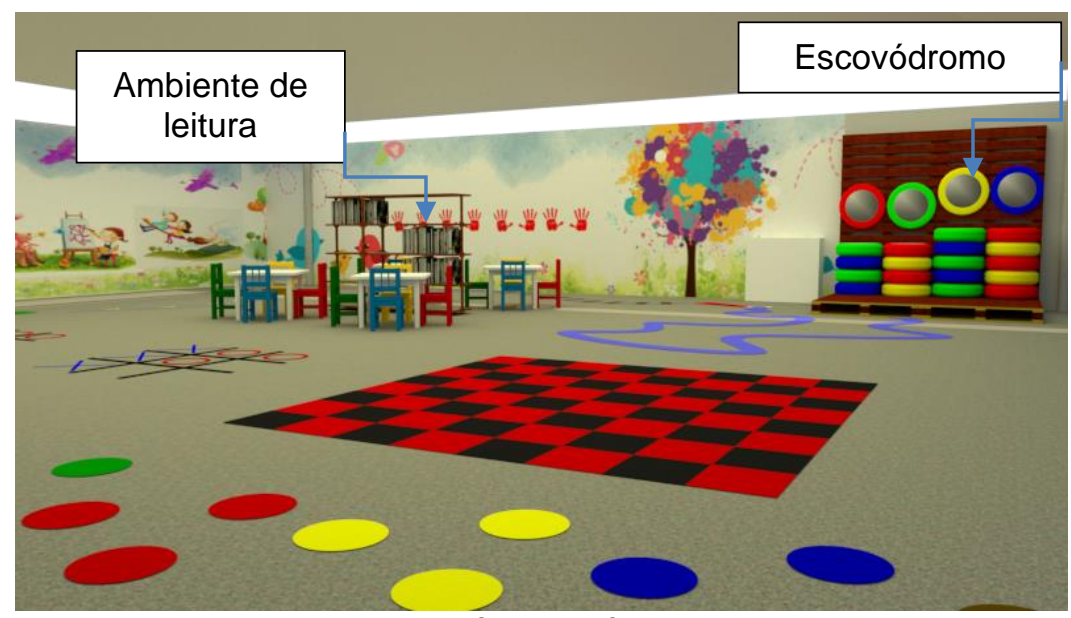

Figura 2: Imagem do projeto do espaço lúdico após intervenção, com pinturas nas paredes realizadas pelas crianças em atividade orientada pelos acadêmicos e professoras em uma escola municipal, no município de Sinop, MT. Fonte: Autores (2020).

Esse espaço foi idealizado para ser utilizado com maior proteção das intempéries, principalmente quando relacionado ao período de chuvas. Pensou-se no desenvolvimento lúdico das crianças com um ambiente colorido.

A ideia central dessa ambientação foi proporcionar conforto e estímulo à criatividade das crianças. A pintura nas paredes seria realizada de forma conjunta, em ação desenvolvida pelos acadêmicos junto com os alunos da IE, orientados pelos professores com relação ao tema e tipo de atividades.

No chão, foi ilustrado e setorizado o espaço de brincadeiras como amarelinha, serpentina de números, jogo da velha, caminho lúdico até o escovódromo, entre outras alternativas (CONSTANTINO, 2010). 
Assinala-se que os espaços lúdicos despertam nas crianças o interesse de percorrer caminhos, descobrir novas possibilidades de brincar, jogar, se divertir. Desse modo, os jogos aguçam a curiosidade, a tentativa de experimentação e a interação com o entorno (CONSTANTINO, 2010). Diante dessa informação, direcionou-se a criação de ambientes mais acolhedores, coloridos, caminhos lúdicos que permitissem a aplicação de várias atividades concomitantes, englobando crianças de idades distintas, promovendo interação e coparticipação no processo de aprendizado.

No caso específico da escola estudada, o ponto de água necessário para o escovódromo já existia; porém a fossa séptica para o destino final do esgoto (visto que a cidade de aplicação do estudo não possui sistema de esgoto) seria construída pelos pais dos alunos, já que muitos são profissionais da construção civil, situação sugerida pela própria diretora da IE. As Figura 3 e 4 expõem a quadra e o jardim sensorial - antes e após a intervenção.

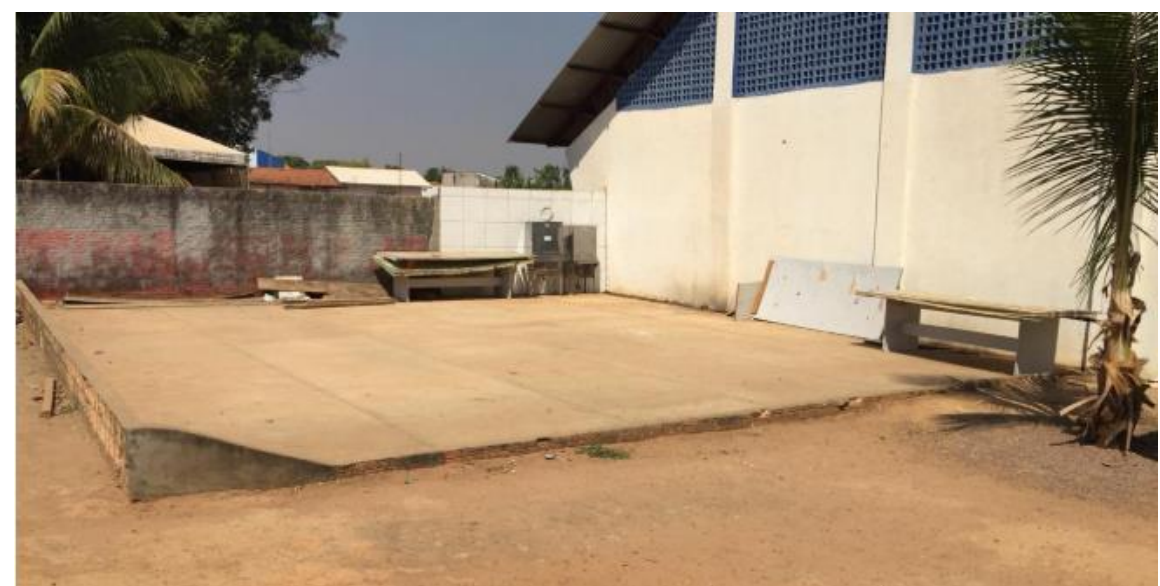

Figura 3: Local da quadra de esportes antes da intervenção em uma escola municipal, no município de Sinop, MT. Fonte: Autores (2020).

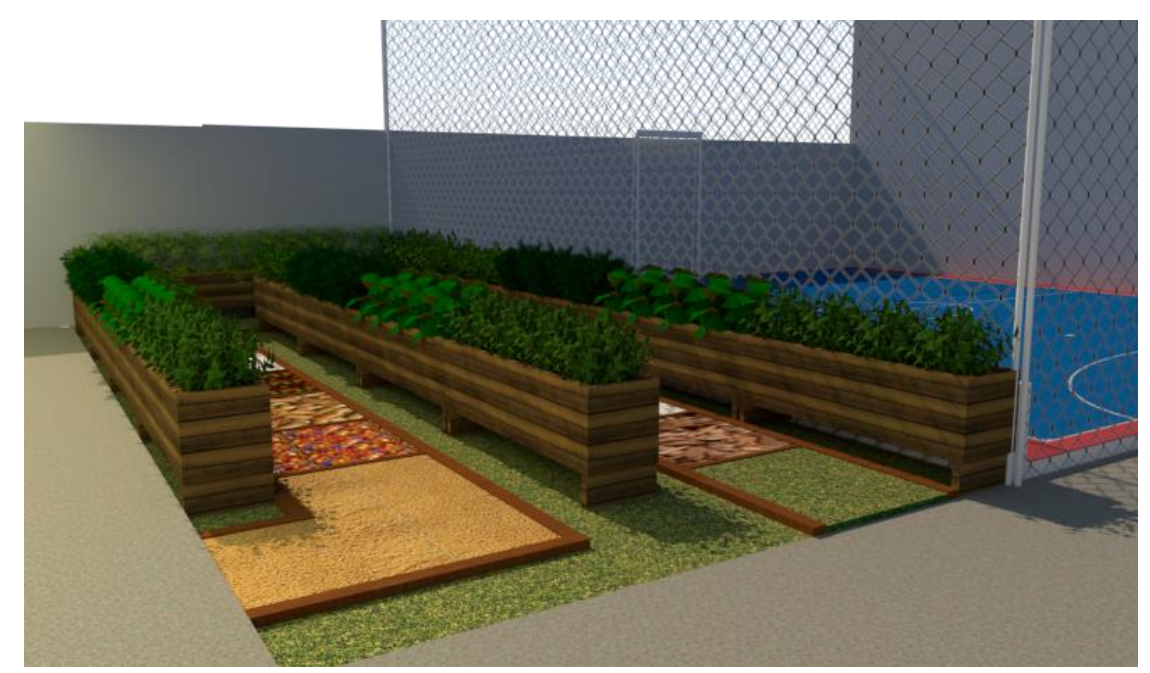

Figura 4: Projeto do jardim sensorial e a quadra (ao lado), após a intervenção, em uma escola municipal, no município de Sinop, MT. Fonte: Autores (2020). 
Antes da intervenção, a quadra não possuía demarcação no piso e estava servindo como depósito de materiais. Esse espaço era pouco utilizado em brincadeiras com bola, pois como observado na Figura 4, a bola rola para os lados, dificultando as atividades das demais crianças.

A Figura 4 mostra o projeto de jardim sensorial elaborado por solicitação do corpo docente da escola com a finalidade de trabalhar principalmente com as crianças especiais em inclusão. Nesse projeto arquitetônico, foram utilizadas plantas aromáticas como alecrim, hortelã, salsinha, arruda, coentro, citronela e erva-cidreira. Foram propostas floreiras confeccionadas com caixas de frutas obtidas nos mercados da cidade, feitas de madeira e/ou plástico e que seriam descartadas pelas empresas, o que contribuiu com a ideia de Educação Ambiental e desenvolvimento sustentável, evitando que esse material fosse direcionado ao descarte inadequado ou queima. O jardim oferece livre acesso e foi pensando de forma acessível, sendo adaptado em sua dimensão para o uso de portadores de necessidades especiais (PCDs). Propõe-se que a manutenção seja feita pelos estudantes juntamente com os professores, aproveitando de forma pedagógica o espaço revitalizado.

Ao longo do jardim foi construída uma pista tátil, com diferentes texturas feitas com pedras, areia, madeira, bolinhas de gude, rolas de garrafa, brita e tampinhas de garrafa de refrigerante que estimulam a percepção do tato e do equilíbrio.

As Figuras 5 a 7 exibem o espaço para atividades das crianças maiores / jogos - antes e depois (interferência em projeto). A planta baixa da escola, após a intervenção, pode ser observada na Figura 8.

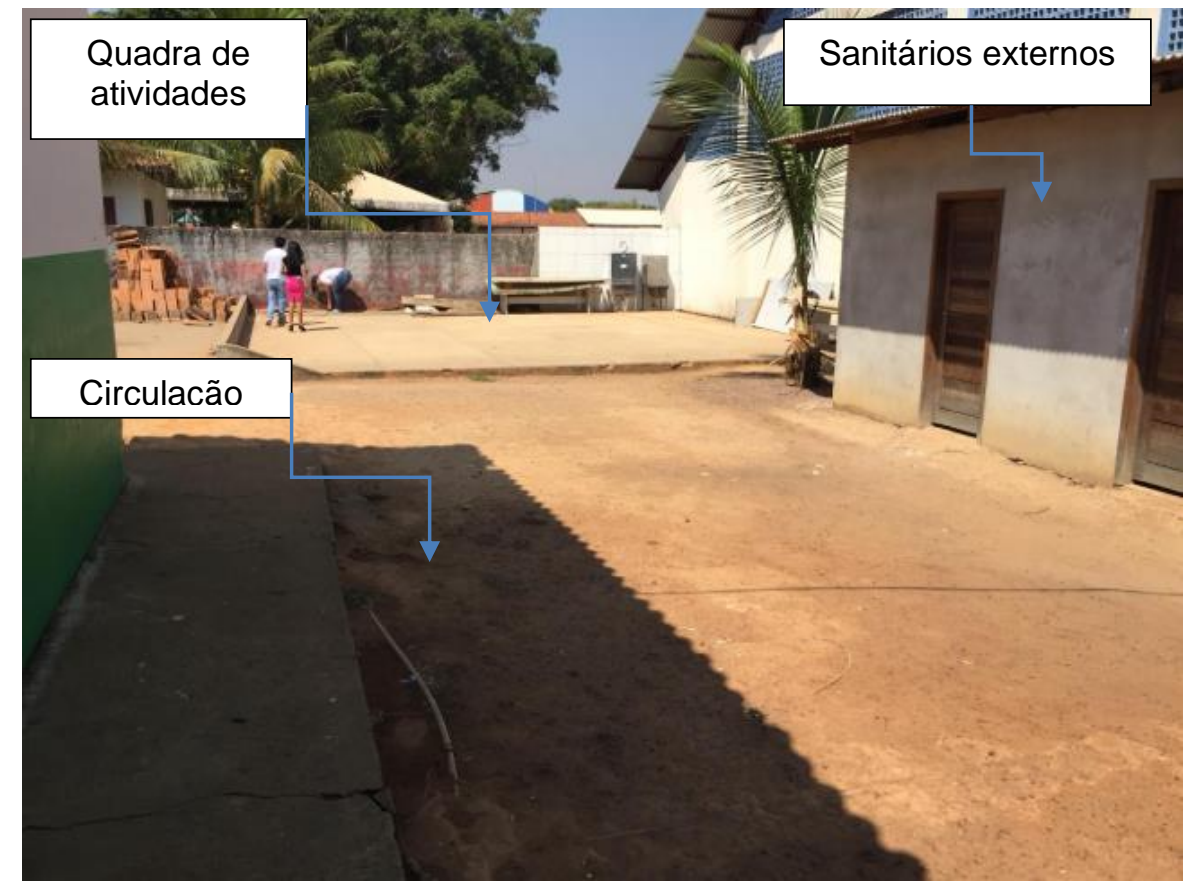

Figura 5: Antes, espaço ocioso utilizado apenas para passagem dos alunos em uma escola municipal, no município de Sinop, MT. Fonte: Autores (2020). 


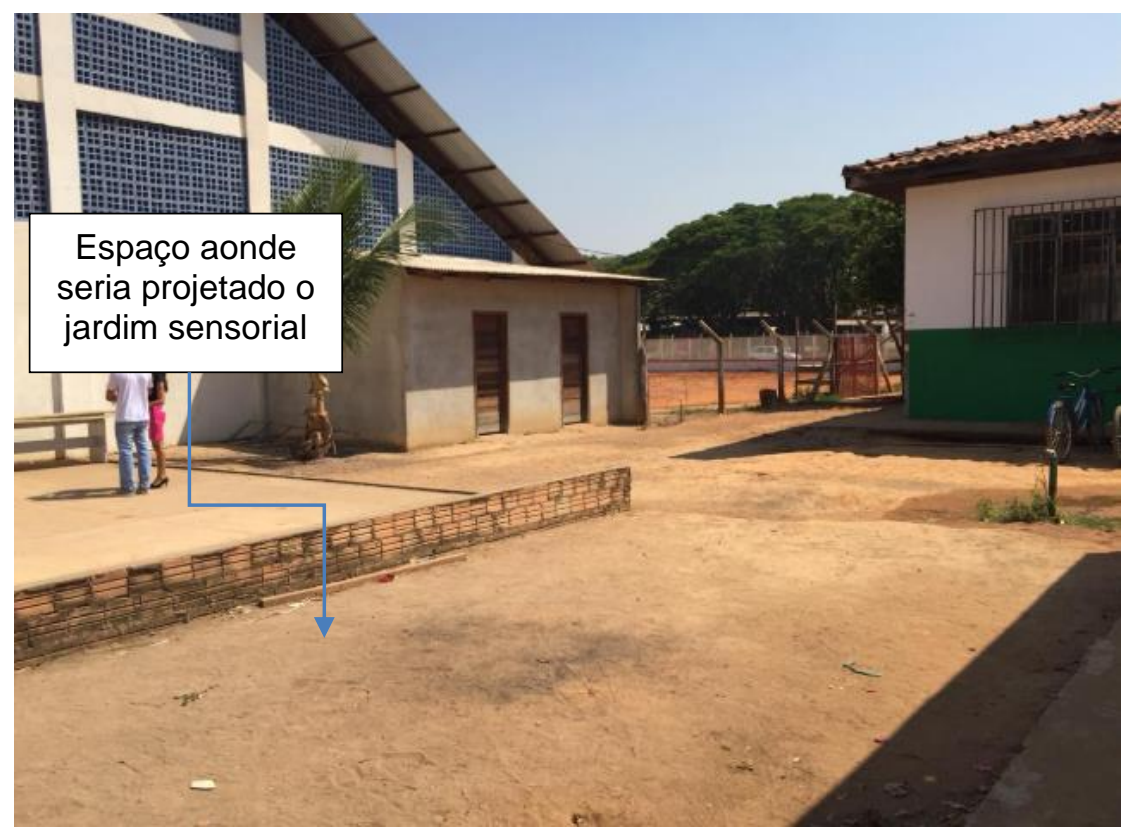

Figura 6: Antes, espaço ocioso utilizado apenas para passagem dos alunos em uma escola municipal, no município de Sinop, MT. Fonte: Autores (2020).

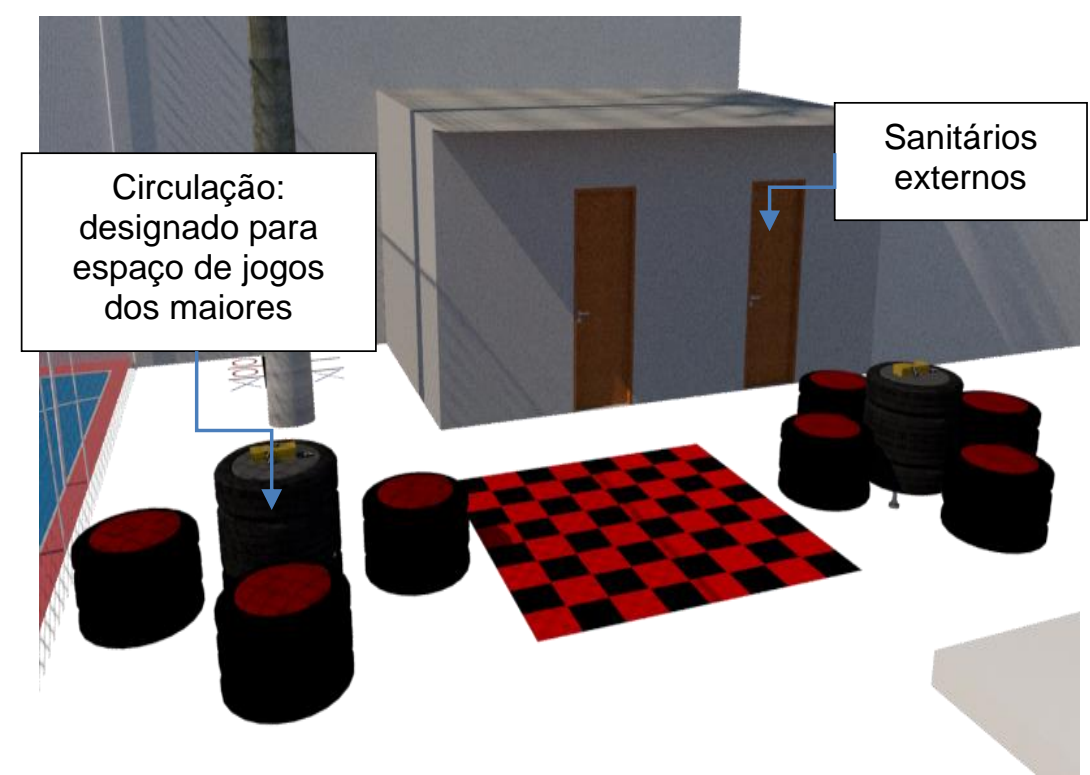

Figura 7: Proposta de projeto, espaço para jogos em uma escola municipal, no município de Sinop, MT. Fonte: Autores (2020).

No projeto, foi proposto espaço para utilização dos alunos maiores, $4^{\mathrm{a}} \mathrm{e}$ 5a séries, trabalhando a integração e a responsabilidade deles com relação aos menores. De acordo com a coordenadora da escola, é necessário incentivar essa inclusão em atividades, o que não estava ocorrendo devido à falta de espaço adequado. 


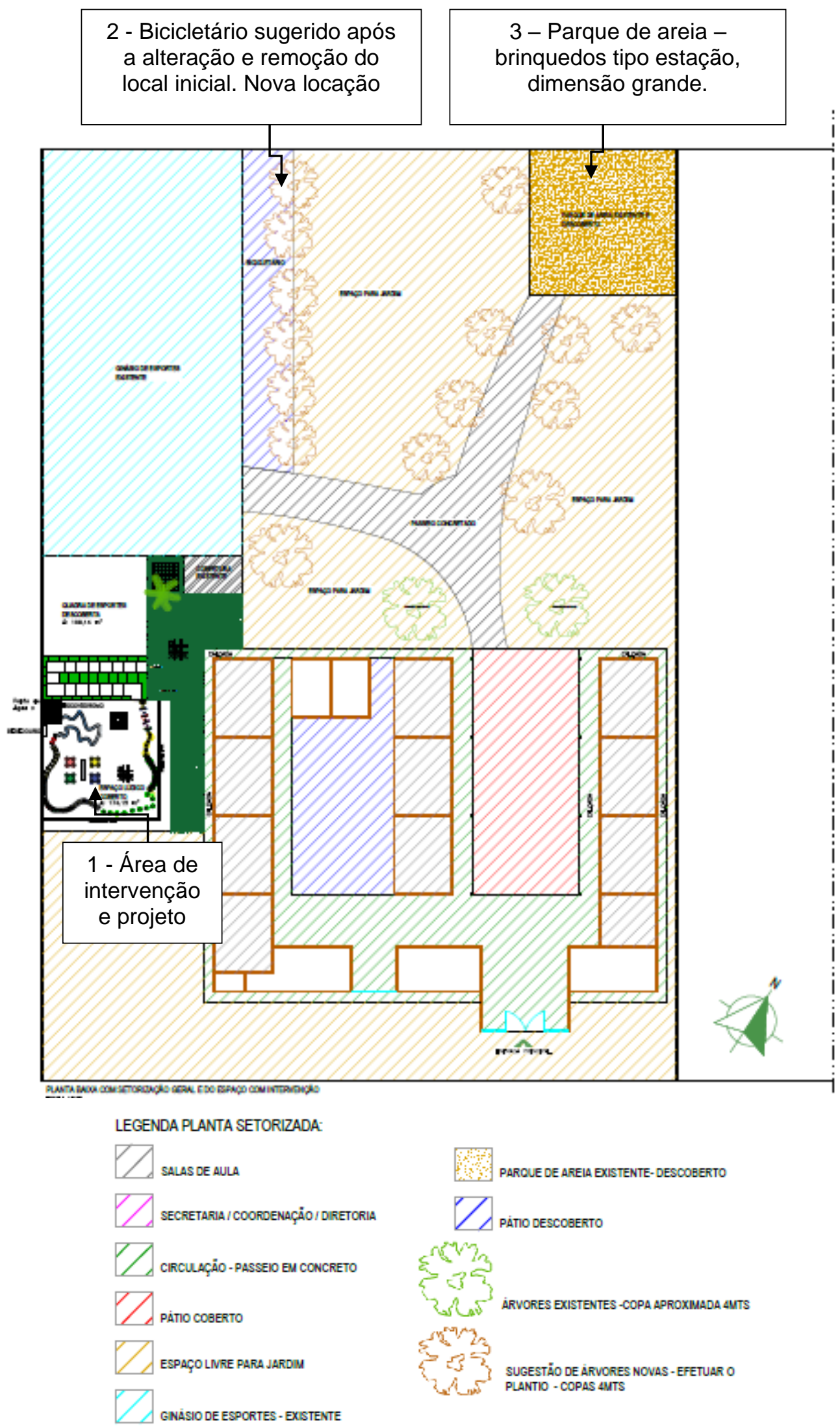

Figura 8: Planta baixa da escola com as demarcações das áreas de intervenção e legenda da setorização em uma escola municipal, no município de Sinop, MT. Fonte: Autores (2020).

Revbea, São Paulo, V. 15, № 7: 224-247, 2020.

revista brasileira educação ambiental 
Foram sugeridos a mudança de local do bicicletário, o plantio de mais árvores, efetuando a proteção dos caminhos de maneira a viabilizar e compatibilizar com as questões de alteração climática, como pode ser observado na Figura 8 (box 1).

Em virtude da remoção do bicicletário (Figura 8, box 2), houve a necessidade de instalá-lo em novo local (Figura 9), visto que muitas crianças vão à escola utilizando transporte ativo, via bicicleta. Para aliviar e proteger as bicicletas do sol da fachada Norte, tomou-se como estratégia a utilização de árvores de grande ou médio porte, aproveitando também para criar um ambiente mais arborizado.

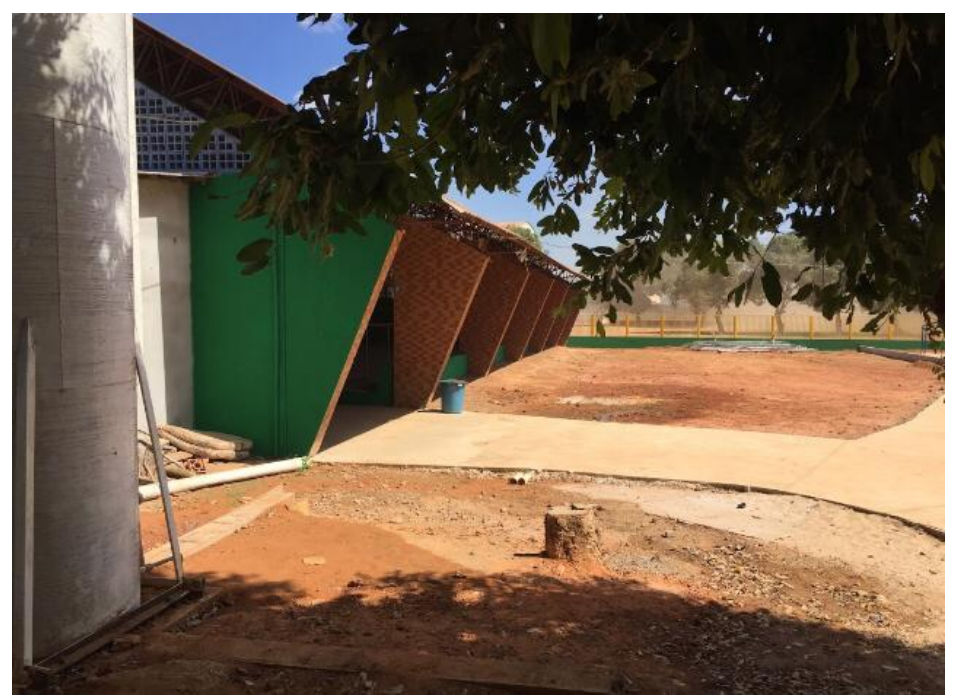

Figura 9: Espaço determinado para novo bicicletário - trabalhando a utilização de árvores como estratégia para proteção solar, em uma escola municipal, no município de Sinop, MT. Fonte: Autores (2020).

No início das medições e visitas técnicas observaram-se grande área ao fundo da escola sem uso definido, amplo espaço com terra batida, sem plantas nem arborização. Com a proposta de intervenção quase finalizada, realizou-se uma visita técnica para fotografar novamente alguns espaços e conferir algumas dimensões. Nesse momento, verificou-se a inserção nesse espaço, voltado para a direção Norte (sol incidindo o dia todo), de um parquinho para as crianças (Figura 8, box 3 ), tipo de estação de atividades confeccionado em material "plástico" e implantado em local sem sombreamento algum. A forma como foi implantado esse parquinho dificultou bastante o plantio de mudas de árvores, pois encontra-se margeando à divisa do terreno com o vizinho.

Sugeriu-se, por meio do projeto, o plantio de árvores de porte alto, voltadas ao leste/nordeste, outras para a região oeste/noroeste, permitindo sombreamento e amenizando o excesso de calor para as crianças no período da manhã e da tarde. Entretanto, no período entre $11 \mathrm{~h}$ e $13 \mathrm{~h}$ em que o sol está mais alto, não seria conveniente a utilização desse ambiente em decorrência do sol excessivo. Esse ambiente não entrou na solicitação de proposta para 
interferência e reforma solicitada pela escola; e os estudantes de Arquitetura e Urbanismo sugeriram uma complementação no projeto, permitindo que pudesse ser realizada conforme as possibilidades da IE (Figura 10).

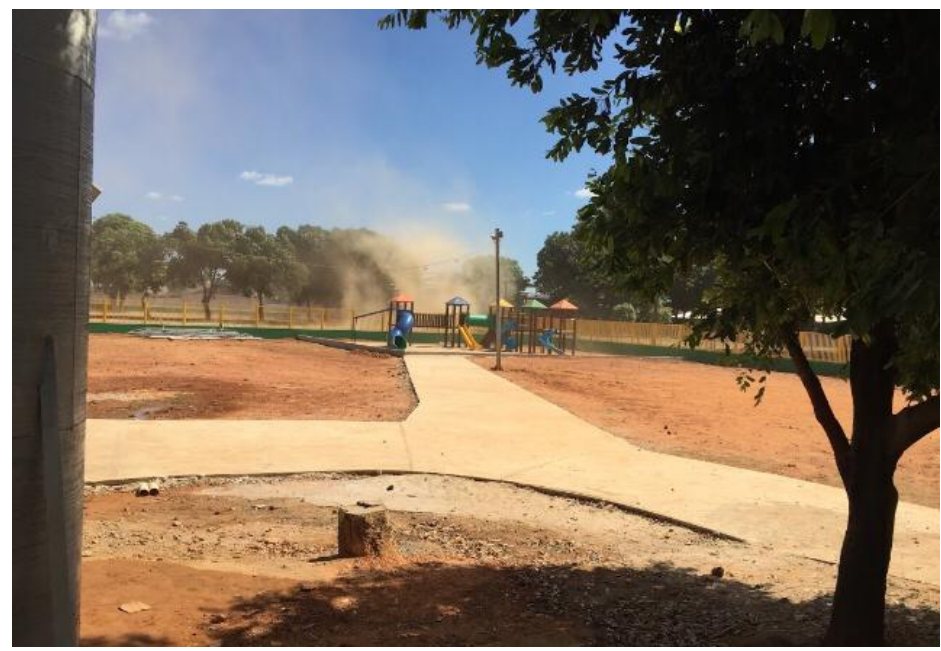

Figura 10: Foto retirada na última visita técnica - no início esse espaço estava oscioso e sem perspectiva de utilização. O parquinho foi implantado no período compreendido entre o início e o término do estudo/projeto., em uma escola municipal, no município de Sinop, MT.

Fonte: Autores (2020).

Não se desconsiderando a importância dos itens solicitados pela IE, que haviam sido solucionados no projeto de arquitetura, sugeriu-se a inclusão de novas árvores e espécies vegetais para melhorar a qualidade de sombreamento, qualidade do ar e redução da velocidade dos ventos (AMATOLOURENÇO et al., 2016), visando à compatibilidade entre a proposta efetiva e a necessidade solicitada. Este poderia ser executado gradativamente de forma particionada, levando-se em conta as possibilidades financeiras.

Em todo espaço livre para jardim, sugeriu-se inicialmente o cultivo de grama para contenção da poeira e melhoria da qualidade visual do espaço, tornando o ambiente mais acolhedor (ALBUQUERQUE; SILVA; KUHNEN, 2016). No que diz respeito às crianças envolvidas, por meio da implantação deste estudo buscou-se propiciar conhecimento sobre temáticas como descarte e aproveitamento de objetos, evitando o encaminhamento para o lixo e/ou queima de materiais, contribuindo com a qualidade do ar e não emissão de poluentes tóxicos dissipados através da fumaça preparo de horta orgânica, reciclagem, alimentação saudável e/ou utilização de ervas aromáticas no dia a dia e preservação ambiental. É importante que o processo de aprendizagem seja desenvolvido com alegria, podendo ser mais produtivo, crítico e reflexivo, proporcionando maiores condições de mudanças na educação e na sociedade (LIMA, 2016).

O indivíduo, ao se sentir integrante do ambiente, vivencia um sentimento de responsabilidade diante da conservação e/ou preservação dos recursos naturais, respeitando o uso e o futuro desse ambiente (DA SILVA et al., 2015). 
Além disso, os benefícios propiciados pela escola sustentável podem ajudar no enfrentamento das repercussões da Covid-19, como diminuição da ansiedade e melhora da capacidade de concentração, melhorando a saúde mental e o bem-estar psicológico (SCHMIDT et al., 2020).

A relação interpessoal também é estimulada por intermédio de atividades programadas, proporcionando a interação entre as crianças de idades diversas, promovendo a valorização dos maiores, sentido de responsabilidade, afetividade e pertencimento. Nos menores, o respeito e a divisão de brinquedos.

A inserção do jardim sensorial surgiu com o intuito de trabalhar o estímulo e o desenvolvimento físico e psicológico dos alunos da IE. Buscou-se propiciar a estes o contato com a natureza, oferecendo-lhes novos espaços para a aprendizagem por cheiros, texturas e cores das plantas e de materiais utilizados na construção do piso, estimulando o equilíbrio e os sentidos clássicos da visão, audição, olfato, paladar e tato (PARANÁ, 2014).

Por se tratar de um projeto de arquitetura desenvolvido de forma independente pela escola solicitante, disponibilizando de poucos recursos financeiros, tornou-se oportuna a participação de pais e alunos na arrecadação e implantação do projeto, conforme desejo da IE. Assim, estimularam-se a valorização do ambiente físico da escola e a redução de danos materiais causados pela falta de cuidado dos alunos, gerando sentimento de pertencimento por envolver a comunidade no processo (CAVALCANTE; ELALI, 2018).

\section{Conclusão}

A Educação Ambiental é parte relevante da formação cidadã de todo indivíduo, determinante no desdobramento da cultura ética das atitudes humanas no contexto socioambiental. Existem diferentes maneiras da inclusão desse tema no ambiente escolar, atrelado a práticas de bem-estar social e desenvolvimento sustentável.

As intervenções ambientais propostas neste estudo contribuem para resgatar o sentimento de pertencimento e integração ao ambiente escolar tão importante após o recesso escolar prolongado devido à Covid-19. Visam ainda ao despertar para a responsabilidade diante da conservação e/ou preservação dos recursos, proporcionando o respeito ao uso presente e futuro desse ambiente.

Este estudo aponta a relação positiva entre natureza-indivíduo, via desenvolvimento da Educação Ambiental por meio de metodologia ativa e integradora, contando com o envolvimento dos membros da escola e familiares em todo o processo. Essa integração proporcionou a experiência de reutilizar materiais que seriam descartados, adquirir o conhecimento sobre a biodiversidade e sensibilização e apreço pelo projeto realizado. 
O projeto fundamenta a necessidade da aplicação de métodos sustentáveis nas escolas a fim de desenvolver a Educação Ambiental, concebida a partir da relação e apreciação com a natureza, aprimorando os indivíduos para problemas atuais e futuros na esfera ambiental, visando a uma sociedade mais consciente e sustentável pós-pandemia. Defende-se a integração social entre educadores, poder público e sociedade para o aprimoramento de políticas públicas direcionadas à Educação Ambiental nas escolas e retomada do caminho histórico da jornada do desenrolar do eixo socioambiental.

\section{Agradecimentos}

Os autores agradecem ao Programa de Pós-Graduação em Tecnologias Limpas (PPGTL) da Universidade Cesumar e ao ICETI (Instituto Cesumar de Ciência, Tecnologia e Inovação) pelo apoio ao desenvolvimento e promoção desta pesquisa. Os autores também agradecem à Coordenação de Aperfeiçoamento de Pessoal de Nível Superior - Brasil (CAPES) pelo apoio financeiro.

\section{Referências}

ALBUQUERQUE, D. S.; SILVA, D. S.; KUHNEN, A. Environmental Preferences and Psychological Restoration possibilities in Universities Campuses. Psicologia: Ciência e Profissão. v. 36, n. 4, p. 893, 2016.

AMATO-LOURENÇO, L. F. et al. Metrópoles, cobertura vegetal, áreas verdes e saúde. Estudos Avançados. v. 30, n. 86, p. 113-130, 2016.

BARATTO, R. Colégio público do Rio de Janeiro é a primeira escola sustentável certificada da América Latina. Archdaily, 02 Jan. 2014. Disponível em: $\quad<$ https://www.archdaily.com.br/br/01-164540/colegio-publico-do-rio-dejaneiro-e-a-primeira-escola-sustentavel-certificada-da-america-latina>. Acesso em: 20 Jun. 2020.

CAMPOS-DE-CARVALHO, M. I.; ROSSETTI-FERREIRA, M. C. Importance of spatial arrangements for young children in day care centers. Children's Environments. v. 10, n. 1, p. 19-30, 1993.

CAVALCANTE, S.; ELALI, G. A. Psicologia ambiental: Conceitos para a leitura da relação pessoa-ambiente. Editora Vozes Limitada, 2018.

CHAWLA, L.; CHAWLA, L.; KEENA, K.; PEVEC, I.; STANLEY, E. Green schoolyards as havens from stress and resources for resilience in childhood and adolescence. Health \& place. v. 28, p. 1-13, 2014.

CHEN, H.; GUO, J.; WANG, C.; LUO, F.; YU, X.; ZHANG, W.; LIAO, J. Clinical characteristics and intrauterine vertical transmission potential of COVID-19 infection in nine pregnant women: a retrospective review of medical records. The Lancet. v. 395, n. 10226, p. 809-815, 2020. 
CLAYTON, Susan et al. Psychological research and global climate change. Nature Climate Change. v. 5, n. 7, p. 640-646, 2015.

COELHO, W. N. B.; COELHO, M. C. Preconceito e discriminação para além das salas de aula: sociabilidades e cultura juvenil no ambiente escolar. Revista do Instituto de Estudos Brasileiros. n. 62, p. 32-53, 2015.

CONSTANTINO, N. R. T. Jardins educativos e terapêuticos como fatores de qualidade de vida urbana. Anais do Congresso Luso-Brasileiro para o Planejamento Urbano, Regional, Integrado, Sustentável. 2010.

COIMBRA, A. S.; FERNANDES, A. A. Sujeitos Coletivos e Educação Ambiental. O papel das ONGs Ambientalistas de Juiz de Fora no Conselho Municipal de Meio Ambiente-COMDEMA-JF. Revista Vianna Sapiens. v. 2, n.1, p. 26, 2017.

COSTANZA, Robert et al. The value of the world's ecosystem services and natural capital. Nature. v. 387, n. 6630, p. 253-260, 1997.

CURSEU, D. et al. Potential impact of climate change on pandemic influenza risk. In: Global Warming. Springer, Boston, MA, 2010. p. 643-657.

DA SILVA, A. M. et al. Comportamentos ambientalmente responsáveis e sua relação com a Educação Ambiental. Revista de Gestão Ambiental e Sustentabilidade. v. 4, n. 1, p. 1-16, 2015.

DA SILVA, R. H. A.; MIGUEL, S. S.; TEIXEIRA, L. S. Problematização como método ativo de ensino-aprendizagem: estudantes de farmácia em cenários de prática. Trabalho, Educação e Saúde. v. 9, n. 1, p. 77-93, 2011.

DA SILVA, L. N. R.; CALIXTO, P. M. Educação Ambiental na escola: promovendo e valorizando o sujeito e o ambiente. Revista Thema. v.14, n.2, p. 25-36, 2017.

OLIVEIRA, M. L.; RUPPENTHAL, J. E. CERTIFICAÇÃO LEED: O INCREMENTO DA INOVAÇÃO NO AMBIENTE CONSTRUÍDO EM RELAÇÃO A SUSTENTABILIDADE. Iberoamerican Journal of Industrial Engineering. v.12, n.23, p. 17-31, 2020.

SOUZA, T. Z. A Educação Ambiental popular: contribuições em práticas sociais. MOTRICIDADES: Revista da Sociedade de Pesquisa Qualitativa em Motricidade Humana. v.2, n.1, p. 60-70, 2018.

SANTOS, J. O. Educação Ambiental: O trabalho desenvolvido por professores de uma escola pública do interior da Paraíba. Revista de Geociências do Nordeste. v.2, p.770-780, 2016.

FENEA (Federação Nacional dos Estudantes de Arquitetura e Urbanismo do Brasil). Carta de definição para Escritórios Modelo de Arquitetura e Urbanismo. Florianópolis, jul 2007. Disponível em: <http://www.fenea.org/artigos/cartadefinicaoemau>. Acesso em: 25 jun 2020. 
FISCHER, L. K. et al. Biodiverse edible schools: Linking healthy food, school gardens and local urban biodiversity. Urban Forestry \& Urban Greening, v. 40, p. 35-43, 2019.

GBC Brasil, Green Building Council. 2012. Disponível em: <http://www.gbcbrasil.org.br>. Acesso em: 4 Ago. 2020.

GIFFORD, R. Psychology's essential role in alleviating the impacts of climate change. Canadian Psychology/psychologie canadienne. v. 49, n. 4, p. 273, 2008.

GROHE, S.L.S. Escolas sustentáveis como proposta de política pública no Brasil. X ANPED SUL. Florianópolis: FAED/UDESC, p. 1429-1, 2014.

HERZOG, T. R., MAGUIRE, P.; NEBEL, M. B. Assessing the restorative components of environments. Journal of environmental psychology. v. 23, n. 2, p. 159-170, 2003.

HIGUCHI, M. I. G.; KUHNEN, A.; PATO, C. Psicologia Ambiental em contextos urbanos. 2019.

JESUS, J. B. D., ROSA, C. N. D., BARRETO, Í. D. D. C., \& FERNANDES, M. $M$. Análise da incidência temporal, espacial e de tendência de fogo nos biomas e unidades de conservação do Brasil. Ciência Florestal, v. 30, n. 1, p. 176191, 2020.

KWEON, B. S.; ELLIS, C. D.; LEE, J.; JACOBS, K. The link between school environments and student academic performance. Urban Forestry \& Urban Greening, v. 23, p. 35-43, 2017.

LIMA, V. V. Espiral construtivista: uma metodologia ativa de ensinoaprendizagem. Interface-Comunicação, Saúde, Educação. v. 21, p. 421-434, 2016.

MEC - Ministério da Educação. Secretaria de Educação Continuada, Alfabetização e Diversidade Diretoria de Educação Integral, Direitos Humanos e Cidadania Coordenação-Geral de Educação Ambiental, 2013. Disponível em: <http://portal.mec.gov.br/dmdocuments/publicaca013.pdf>. Acesso em: 24 Ago. 2020.

MORAES, Denise. Bioma Amazônia. Invivo. Fiocruz. Disponível em: $<$ http://www.invivo.fiocruz.br/cgi/cgilua.exe/sys/start.htm?infoid=958\&sid=2\#: :.t ext=Na\%20regi\%C3\%A30\%20amaz\%C3\%B4nica\%20chove\%20bastante,pr\% C3\%B3ximas\%20\%C3\%A0\%20linha\%20do\%20Equador>. Acesso em: 26 Jun. 2020.

MOSER, G. Psicologia Ambiental e estudos pessoas-ambiente: que tipo de colaboração multidisciplinar? Psicologia Usp. v. 16, n. 1-2, p. 131-140, 2005.

MUHAMMAD, S.; LONG, X.; SALMAN, M. COVID-19 pandemic and environmental pollution: a blessing in disguise? Science of The Total Environment, p. 138820, 2020. 
MUSTAPA, N. D.; MALIKI, N. Z.; HAMZAH, A. Repositioning children's developmental needs in space planning: A review of connection to nature. Procedia-Social and Behavioral Sciences, v. 170, p. 330-339, 2015.

ONU - NAÇÕES UNIDAS BRASIL. 17 Objetivos para transformar nosso mundo, 2015. Disponível em: <https://nacoesunidas.org/pos2015/>. Acesso em: 28 Out. 2019.

PATO, C. M. L.; DELABRIDA, Z. N. C. Proposta transdisciplinar em contextos formativos: chave mestra para a sustentabilidade. Psicologia ambiental em contextos urbanos. Florianópolis, SC: Edições do bosque/CFH/UFSC, p. 3458, 2019.

PINHEIRO, J. Q.; CAVALCANTI, G. R. C.; BARROS, H. C. L. Mudanças climáticas globais: Viés de percepção, tempo e espaço. Estudos de Psicologia (Natal), v. 23, n. 3, p. 282-292, 2018.

REI, F. C. F.; GONÇALVES, A. F.; SOUZA, L. P. Acordo de Paris: Reflexões e desafios para o regime internacional de mudanças climáticas. Veredas do Direito: Direito Ambiental e Desenvolvimento Sustentável, v. 14, n. 29, p. 81-99, 2017.

RIBEIRO, A. I.; TAVARES, C.; GUTTENTAG, A.; BARROS, H. Association between neighbourhood green space and biological markers in school-aged children. Findings from the Generation XXI birth cohort. Environment international, v. 132, p. 105070, 2019.

RIBEIRO, S. L. Espaço escolar: um elemento (in) visível no currículo. Sitientibus, Feira de Santana, v. 31, p. 103-18, 2004.

SILVA PIÑEIRO, R. Los proyectos de caminata rumbo a la escuela para el conocimiento del entorno y favorecer actitudes y hábitos saludables desde educación infantil. Educación, v. 27, n. 53, p. 177-202, 2018.

SAUVÉ, L. Educação Ambiental: possibilidades e limitações. Educação e Pesquisa, v. 31, n. 2, p. 317- 322, 2005.

SECRETARIA DA EDUCAÇÃO DO ESTADO DO PARANÁ. Jardim sensorial estimula desenvolvimento de alunos, 2014. Disponível em: $<$ http://www.educacao.pr.gov.br/Noticia/Jardim-sensorial-estimula-

desenvolvimento-de-alunos>. Acesso em: 15 Ago. 2019.

SCHMIDT, B.; CREPALDI, M. A.; BOLZE, S. D. A., NEIVA-SILVA, L.; DEMENECH, L. M. Saúde mental e intervenções psicológicas diante da pandemia do novo coronavírus (COVID-19). Estudos de Psicologia (Campinas), v. 37, 2020.

TEIXEIRA, T. S.; MARQUES, É. A.; PEREIRA, J. R. Educação Ambiental em escolas públicas: caminho para adultos mais conscientes. Revista Ciência em Extensão, v. 13, n. 1, p. 64-71, 2017. 
THOMPSON, C. W. ROE, J.; ASPINALL, P.; MITCHELL, R.; CLOW, A.; MILLER, $D$. More green space is linked to less stress in deprived communities: Evidence from salivary cortisol patterns. Landscape and urban planning, v. 105, n. 3, p. 221-229, 2012.

VASCONCELOS, C. A. Possibilidades para a inserção da Educação Ambiental na formação docente. Revista Espaço Pedagógico, vol. 3, n. 1, p. 112-132, 2017.

WHITMARSH, L. Scepticism and uncertainty about climate change: Dimensions, determinants and change over time. Global environmental change, v. 21, n. 2, p. 690-700, 2011.

WOLSINK, M. Environmental education excursions and proximity to urban green space-densification in a 'compact city'. Environmental Education Research, v. 22, n. 7, p. 1049-1071, 2016.

ZHAO, D. X.; HE, B. J.; MENG, F. Q. The green school project: A means of speeding up sustainable development? Geoforum, v. 65, p. 310-313, 2015. 